\title{
GESTÃO DEMOCRÁTICA NA ESCOLA PÚBLICA: CONCEITO, DESAFIOS E POSSIBILIDADES.
}

Mariana Aparecida de Almeida Laurentino, Vanda Moreira Machado Lima

Universidade Estadual Paulista - UNESP, Pedagogia, Presidente Prudente, SP. E-mail:mary_ana185@hotmail.com. Agência de fomento: PIBIC/Reitoria

\section{RESUMO}

Este artigo apresenta um recorte da pesquisa de iniciação científica (PIBIC/Reitoria UNESP) que investigou os desafios recorrentes da implantação da gestão democrática na escola pública municipal a partir da visão da equipe escolar. Contudo, este artigo visa refletir sobre a gestão democrática a partir da opinião da equipe escolar (diretor, vice diretor, coordenador pedagógico, professores, funcionários e famílias) enfatizando conceito, desafios e possibilidades. A pesquisa se insere na abordagem qualitativa e, utilizamos na coleta de dados: pesquisa bibliográfica, observações e entrevistas.Os dados empíricos evidenciaram que a percepção dos entrevistados a respeito da gestão democrática na escola faz-se presente através da promoção de atividades que requerem a presença/envolvimento dos segmentos, assim como por meio da consciência e luta da equipe escolar por uma escola mais justa e democrática.

Palavras-chave: Gestão democrática, Escola pública municipal, equipe escolar, desafios, possibilidades.

\section{DEMOCRATIC MANAGEMENT IN PUBLIC SCHOOL: CONCEPT, CHALLENGES AND POSSIBILITIES.}

\begin{abstract}
This article presents part of scientific initiation research (PIBIC / Rectory UNESP) that investigated the recurring challenges of implementation of democratic management in the public school from the school team vision. However, this article aims to reflect on the democratic management from the view of school staff (director, deputy director, pedagogical coordinator, teachers, staff and families) emphasizing concept, challenges and possibilities. The research is inserted in the qualitative approach, used in data collection: bibliographical research, observations and entrevistas.Os empirical data showed that the perception of respondents about the democratic management in school is present by promoting activities that require presence / involvement of the segments as well as through awareness and fight the school staff for a more just and democratic school.
\end{abstract}

Keywords: Democratic management, municipal public school, school staff, challenges, possibilities. 


\section{INTRODUÇÃO}

A criação de um clima propício à aprendizagem e de qualidade ao ensino, é algo que depende, dentre outros fatores, essencialmente da capacidade do coletivo da escola de gerar um ambiente de formação crítica, de respeito mútuo e de participação de todos os atores do processo educativo. Para isso, a gestão da escola precisa ser democrática e participativa, na qual segundo Libâneo; Oliveira; Toschi (2012, p.447) esta forma de gestão "baseia-se na relação orgânica entre a direção e a participação dos membros da equipe" defendendo a ideia de tomada de decisão no coletivo.

Vale ressaltar que a gestão democrática é obrigatória na educação básica nas instituições de ensino público, conforme a Lei de Diretrizes e Bases da Educação Nacional n. 9394/96 (LDB/96), que estabelece a gestão democrática do ensino público na educação básica, mediante a “I - participação dos profissionais da educação na elaboração do projeto pedagógico da escola; II participação das comunidades escolar e local em conselhos escolares ou equivalentes" (BRASIL, 1996, art.14).

A gestão democrática possibilita igualdade e solidariedade na escola, além de fortalecer a integração escola-comunidade, visto que visa discussões coletivas desenvolvidas com respeito a fala do outro. Numa escola democrática os sujeitos envolvidos têm o direito de concordarem ou discordarem e debaterem se julgarem necessário, até chegarem a um consenso (ponto chave para a efetivação da democracia). Portanto, as escolas democráticas são caracterizadas como espaços de justiça, igualdade e integridade (BERALDO; PELOZO, 2007).

Este artigo apresenta um recorte da pesquisa de iniciação científica (PIBIC/Reitoria UNESP) que investigou os desafios recorrentes da implantação da gestão democrática na escola pública municipal a partir da visão da equipe escolar. Contudo, este artigo visa refletir sobre a gestão democrática a partir da opinião da equipe escolar (diretor, vice diretor, coordenador pedagógico, professores, funcionários e famílias) enfatizando conceito, desafios e possibilidades.

\section{METODOLOGIA}

Nossa pesquisa é desenvolvida em uma escola pública municipal ciclo I do Ensino Fundamental, situada no interior do Estado de São Paulo. Desenvolvemos a pesquisa na abordagem qualitativa, que segundo Godoy (1995) permite que o pesquisador analise o ponto de vista de todos os participantes, levando em conta tudo aquilo que é dito e apresentado ao pesquisador.

Como instrumentos na coleta de dados utilizamos: pesquisa bibliográfica, observações e entrevistas. A pesquisa bibliográfica refere-se ao levantamento e seleção da bibliografia publicada sobre o tema de estudo, com o objetivo de colocar o pesquisador em contato direto com todo o material já escrito sobre o assunto (LAKATOS; MARCONI, 1987).

A observação participante permite que o pesquisador se envolva "com os sujeitos em seu cotidiano, tentando sentir o que significa estar naquela situação" (REYS; MONTEIRO, 2010, p. 19), isto é, o pesquisador pode se colocar no lugar do sujeito observado, a fim de que sua visão possa ampliar a compreensão do comportamento ou das ações do sujeito. Desenvolvemos 54 horas de observações, no período entre setembro e dezembro de 2015.

Quanto a entrevista, evidenciamos a influência recíproca entre quem pergunta e quem responde, possibilitando correções, esclarecimentos e adaptações que tornaram eficaz a obtenção das informações desejadas (LÜDKE, ANDRÉ, 1986). A entrevista explora o que a pessoa sabe, crê, espera, sente e deseja. Além de ser um momento de organização de ideias cujo significado é construído na interação. Realizamos cinco entrevistas, envolvendo a diretora, a vice, a coordenadora pedagógica, um funcionário que trabalha na secretaria da escola e uma professora da escola. Está pesquisa foi aprovada pelo Comitê de Ética em Pesquisa (CEP) da FCT/UNESP com número 30366414.0000 .5402$. 


\section{RESULTADOS}

Como resultados selecionamos algumas categorias: perfil dos sujeitos, conceito de Gestão democrática; desafios e possibilidade na implantação da gestão democrática.

\section{PERFIL DOS SUJEITOS ENTREVSTADOS}

Os sujeitos entrevistados foram quatro do sexo feminino e apenas o funcionário do sexo masculino. A diretora da escola um ano e meio nesta escola como diretora, remanejada de outra unidade escolar, na qual entrou por concurso. Formada há 20 anos já atuou na rede municipal como diretora, professora e coordenadora em outras escolas. Além de ocupar o cargo de direção, atua como professora de uma Universidade particular, pois possui o título de mestre. A vice diretora da escola trabalha a mais de vinte anos nesta escola ocupando inicialmente a função de professora por concurso, e exerce a função de vice diretora nesta escola a mais de quinze anos. A coordenadora trabalha a mais de dez anos na escola, ocupando a função de professora por meio de concurso e há três anos exerce a função de coordenadora. A professora ingressou por concurso e trabalha a mais de vinte anos nesta unidade. Ocupa o cargo de professora e também a função de coordenação do Programa Mais Educação. O funcionário concursado trabalha a um ano e meio nesta escola como oficial de escola- antigo secretário escolar. Em 2015 era aluno do 20ano do curso de Pedagogia.

\section{CONCEITO DE GESTÃO DEMOCRÁTICA}

A maioria dos entrevistados compreende o conceito de gestão democrática envolvendo temas básicos como: desenvolver um trabalho coletivo, baseado no diálogo e nos princípios da participação de todos nas tomadas de decisões da escola. A gestão democrática relaciona-se a um processo, que requer paciência, compromisso e participação dos envolvidos. Essa gestão se constrói gradativamente no cotidiano escolar e só é possível no conjunto, quando o coletivo colabora. Os entrevistados entendem que promover parcerias pode auxiliar na implementação da gestão democrática com olhares voltados para essa construção.

[...] toda comunidade escolar trabalhando em busca de um mesmo objetivo (Entrevista do funcionário).

[...] onde a gente pode ou consiga uma participação maior de comunidade escolar, funcionários, os professores (Entrevista da Coordenadora)

[...] olhar pro coletivo sempre eu acho que essa é a gestão democrática tentar ser parceiros [...] Pra esse não convencimento, porque quando você tenta o convencimento a pessoa nem sempre vem inteira [...] Mas o olhar pra essa construção é isso (Entrevista da Diretora).

\section{DESAFIOS E POSSIBILIDADE NA IMPLANTAÇÃO DA GESTÃO DEMOCRÁTICA}

Em relação aos desafios em promover a gestão democrática os entrevistados afirmam ser complexo por diversos motivos, apontados como:

- desconhecimento da importância de se efetivar tal gestão na escola e mesmo o desinteresse de alguns sujeitos;

- cultura escolar, visto que os costumes arraigados de todos os segmentos impedem desenvolver essa forma de gestão;

- construção de um consenso devido às divergências nas ideias, opiniões e crenças;

- ausência de apoio do Departamento de educação do município na implementação da gestão democrática na escola, afinal sabem que tal gestão está prevista em lei, porém em alguns momentos eles próprios dificultam a construção da gestão democrática, dando ordens a escola, ferindo sua autonomia;

- ausência de apoio e incentivo ao trabalho do professor; 
- ausência da participação dos alunos.

Em um momento de discussões percebe-se a falta de argumentos e justificativas plausíveis sobre o assunto. Muitas vezes o diretor pensa em algo para a escola baseado em boas teorias, porém o grupo discorda e mesmo ele sabendo que o melhor seria realizar tal ação, acaba atendendo o que a maioria do grupo decide, respeitando o coletivo. Compreendo isso como um grande desafio na função da direção, pois o diretor vai de encontro com tudo o que acredita para atender o interesse do coletivo e muitas vezes erra e é criticado.

A ausência de participação dos pais nas atividades de seus filhos na escola é mencionada por todos os entrevistados. Todos apontando que se houvesse maior participação o trabalho desenvolvido seria melhor executado, pois o olhar dos pais traria sugestões novas em que a própria equipe escolar não teria pensado.

No entanto, penso que a escola não pode ficar presa a participação dos pais, deve incentivar e valorizar a participação sempre, mas em muitos casos os pais não participam por falta de tempo. Contudo, destinar a melhoria ou o fracasso da aprendizagem dos alunos aos pais é um erro absurdo, pois o responsável pelo ensino e aprendizagem dos alunos é a escola. Os pais deveriam auxiliar, visto que essa participação pode contribuir com o avanço da aprendizagem de seu filho, porém não podemos atribuir toda responsabilidade a eles.

Difícil [...] Devido ao fato de que nem todos os membros da comunidade escolar queiram fazer parte da gestão (Entrevista do funcionário).

[...] a democracia é difícil né, porque você tem que respeitar a ideia do outro [...] um bingo é legal é, um dia das mães um café pras mães é legal, mas você faz uma reunião de bimestre vem 15 pais, 12 pais (Entrevista da Coordenadora).

As sugestões de ações para desenvolver na escola uma gestão democrática estão relacionadas:

- ao trabalho coletivo em comum acordo;

- ao esclarecimento aos pais, professores e funcionários sobre a importância da sua participação para o bom desenvolvimento da escola, estimulando a sua participação;

- a discussão com os pais a respeito do conceito/importância da gestão democrática e dos colegiados existentes na escola e que estão abertos para participação;

- a revisão dos paradigmas educacionais e promoção de atividades interativas entre a escola e famílias.

É preciso que o coletivo se envolva e se comprometa com a gestão democrática, a preparação é muito importante e deve ser feita por meio de leituras de modo a alargar o conhecimento sobre educação.

O acolhimento e o saber ouvir o outro são princípios bases para um bom convívio, pois é fundamental entender o que o outro tem a dizer e posteriormente saber articular com o que foi dito. Para isso é preciso que haja um diálogo com conhecimento, com propriedade para que as duas partes possam compreender o que está sendo proposto. A relação social, a construção de conhecimento e o diálogo são apontados como a função da escola, pois sem isso ela perde o motivo da sua existência. As palavras chaves apontadas para a efetivação da gestão democrática na escola seriam: conscientização, esclarecimento, reflexão, diálogo, comprometimento, conhecimento e paciência.

[...] toda a equipe se trabalhar em comum acordo, coordenação, vice diretor e diretor[...] A gestão democrática pode acontecer sim, tem que fazer meios, procura meios pra que a participação dos pais seja mais ativa, [...] é mais simples de poder fazer com que o funcionário se dedique mais com a escola, porque é o ambiente de trabalho [...] os pais precisam sim, 
ser mais estimulados pela parte da própria escola (Entrevista da funcionário).

[...] Então o diálogo em primeiro momento, mas o diálogo com conhecimento [...] você tem que mostrar o conhecimento [...] eu acho que tudo na escola é o diálogo, é o convencimento, é a relação social o mais importante na escola [...] e se nós perdemos isso, nós perdemos a função da escola, porque senão nós estaremos aqui só pra função automática, de transmissão de conhecimento e não construção de conhecimento, de diálogo (Entrevista da Diretora).

Os entrevistados citaram algumas ações desenvolvidas na escola que se relacionam com a gestão democrática, como:

- funcionamento adequado dos órgãos colegiados (APM, Conselhos, Reunião de pais);

- promoção de atividades de atendimento, interação, formação e conscientização as famílias, de modo que elas participem mais das atividades da escola e da vida dos seus filhos;

- diálogo, socialização e compartilhamento de ideias e problemas que envolvem a escola, consultando e permitindo que todos os envolvidos no processo possam opinar sobre qualquer assunto em discussão. Momentos de discussão de modo que os sujeitos possam expor suas angústias, porém discussões com propriedade para que o grupo perceba que a proposta feita não é para agradar a equipe gestora e sim porque é o melhor a se fazer e, estes momentos proporcionam um clima de confiança entre o grupo;

- parcerias entre a equipe escolar e outras instituições externas a escola em busca de resultados positivos no processo de ensino e aprendizagem dos alunos;

- luta pela conquista da autonomia da escola por meio de ações da equipe gestora junto ao Departamento de Educação municipal, mantendo o foco e insistindo nas necessidades da escola;

- autonomia ao professor em seu trabalho, mesmo com as atividades curriculares obrigatórias a serem desenvolvidas durante o ano, cabe ao professor escolher/analisar qual atividade será desenvolvida com seus alunos;

- matriz curricular da escola permite que os professores trabalhem com seus alunos conteúdos diversificados como: ambiente, higiene, saúde, alimentação e isso faz com que os professores conscientizem seus alunos, entendendo que a função da escola vai além de apenas transmitir conhecimento;

- entendimento e respeito de que aos diversos pensamentos e crenças existentes dentro da escola, podem contribuir para a própria formação cidadã dos alunos, pois tudo que é dito a eles dentro da escola, eles entendem que é um dever e é o certo, para tanto se queremos alunos que respeitem a diversidade devemos dentro da escola promover discussões, momentos em que eles possam se conscientizar sobre suas ações.

\section{DISCUSSÃO}

Os dados empíricos evidenciaram que a percepção dos entrevistados a respeito da gestão democrática na escola faz-se presente através da promoção de atividades que requerem a presença/envolvimento dos diversos segmentos, assim como por meio da consciência e luta da equipe escolar por uma escola mais justa e democrática.

No entanto, a partir da análise das entrevistas fica claro que esta escola tem buscado construir uma gestão democrática em virtudes das ações já desenvolvidas. Contudo a democracia é algo complexo de ser promovido na escola, devido aos diversos pensamentos e crenças e ao compromisso que cada segmento assume. De acordo com Ferreira e Sturmer (2010, p.159)

A trajetória de construção da escola democrática, portanto, depende da ampliação do grau de conhecimento dos professores e das comunidades 
escolares acerca da importância da democratização da escola pública, dos mecanismos de participação na vida da escola, bem como dos instrumentos de gestão escolar (projeto pedagógico, regimento escolar e outros).

Diante disso, percebemos a importância que cada sujeito possui para a democratização do ensino. Entendemos também, que o compromisso pela democratização deve ser assumido por todos, essencialmente pela equipe escolar, pois é ela que desenvolverá essa forma de gestão na escola, assim como se beneficiará dos seus resultados.

\section{CONCLUSÃO}

O conceito de gestão democrática se assemelha com o processo político, em que os envolvidos se reúnem, refletem, discutem e buscam uma solução por meio de tomada de decisão, é nesse "espaço que as pessoas têm oportunidade de expor suas aspirações e dar suas opiniões a respeito do que esperam da escola [...] Os colegiados são instrumentos de participação [...] favorecendo então a difusão e a integração de ideais e saberes que auxiliam no desenvolvimento educacional" (LUIZ, 2010, p. 28-29).

A construção de uma escola pública justa e democrática com ensino de qualidade requer algumas ações como: esclarecer o papel de cada membro da equipe escolar, compreender a importância e conceito da gestão democrática, discutir posturas e ações que tenham presentes os princípios da gestão democrática, etc.

Interessante notar que a lei prevê a gestão democrática nas escolas públicas, porém não assegura sua implementação. Constatamos alguns fatores que a impedem, tais como: descompromisso com a democracia, desconhecimento do conceito e importância da gestão democrática na escola entre outros.

Enfim, precisamos elaborar uma cultura participativa nas escolas, afinal

A gestão compartilhada em suas diferentes formas de conselhos, colegiados etc. precisa desenvolver uma cultura participativa nova que altere as mentalidades, os valores, a forma de conceber a gestão pública em nome dos direitos da maioria e não de grupos lobistas. Isso implica a criação de coletivos que desenvolvam saberes [...] saberes que orientem as práticas sociais, que construam novos valores, aqui entendidos como a participação de coletivos de pessoas diferentes com metas iguais. (GOHN, 2006, p. 36).

\section{REFERÊNCIAS}

BRASIL. Lei n. 9.394, de 20 de dezembro de 1996. Estabelecer as diretrizes e bases da educação nacional. Diário Oficial da União, 23 dez. 1996.

BERALDO, F.; PELOZO, R. de C. B. A GESTÃO PARTICIPATIVA NA ESCOLA PÚBLICA:tendências e perspectivas. Garça. Revista científica eletrônica de pedagogia. Ano V - Número 10 - Julho de 2007- Periódicos Semestral.

FERREIRA, L. S.; STURMER, A. B. A gestão democrática nas escolas públicas de Santa Catarina.Educação: Revista do Centro de Educação UFSM, Vol 35, Iss 1, p. 155-168 (2010).

GODOY A. S. Pesquisa qualitativa:tipos fundamentais. Revista de Administração de Empresas. São Paulo, v. 35, n.3, p, 20-29 Mai./Jun. 1995. 
GOHN, M.G. Educação Não-formal, Participação da Sociedade Civil e Estruturas colegiadas nas Escolas. Ensaio: avaliação e políticas públicas em educação. Rio de Janeiro, v.14, n. 50, p. 27-38, jan./mar. 2006.

LAKATOS, E. M.; MARCONI, M. A. Metodologia do Trabalho Científico. 2. ed. São Paulo: Atlas, 1987.

LIBÂNEO, J. C.; OLIVEIRA, J. F.; TOSCHI, M. S. Educação Escolar:políticas, estrutura e organização. São Paulo: Cortez, 2012. 543 p.

LÜDKE, M, ANDRÉ, M. Pesquisa em educação: abordagens qualitativas. São Paulo. EPU, 1986. 99p.

LUIZ, M. C. Algumas reflexões sobre a prática da gestão democrática na cultura e organização escolar. Revista Eletrônica de Educação, Vol 4, Iss 2, Pp 20-36, 2010.

2010.

REYS, C. R.; MONTEIRO, H. M. Olhando e observando. In: REYS, C. R.; MONTEIRO, H. M. Um olhar crítico- reflexivo diante da realidade educacional.São Carlos: EdUFSCar, 2010. p. 11-29. 